\title{
Densification of Lithium Disilicate under High Pressure Investigated by XPS
}

\author{
Silvio Buchner ${ }^{1}$, Cláudio Radtke ${ }^{2}$, Naira Maria Balzaretti ${ }^{1}$ \\ ${ }^{1}$ Institute of Physics, Universidade Federal do Rio Grande do Sul, Porto Alegre, Brazil \\ ${ }^{2}$ Institute of Chemistry, Universidade Federal do Rio Grande do Sul, Porto Alegre, Brazil \\ Email: naira@if.ufrgs.br
}

Received December 19, 2012; revised January 18, 2013; accepted February 4, 2013

Copyright (C) 2013 Silvio Buchner et al. This is an open access article distributed under the Creative Commons Attribution License, which permits unrestricted use, distribution, and reproduction in any medium, provided the original work is properly cited.

\begin{abstract}
The aim of this work was to investigate by X-ray photoelectron spectroscopy the effect of high pressure on the chemical environments of $\mathrm{Si} 2 \mathrm{p}, \mathrm{O}$ 1s and $\mathrm{Li} 1 \mathrm{~s}$ in lithium disilicate glass ceramic with stoichiometric composition $\mathrm{Li}_{2} \mathrm{O} \cdot 2 \mathrm{SiO}_{2}$ $\left(\mathrm{LS}_{2}\right)$. A group of samples was processed at $2.5 \mathrm{GPa}, 4 \mathrm{GPa}$ and $7.7 \mathrm{GPa}$ at room temperature and a second group was crystallized under high pressure and high temperature. Large shifts of the binding energy toward higher energies were observed in the X-ray photoelectron spectroscopy spectra for samples of the first group after densification at 2.5 and 4 $\mathrm{GPa}$. For samples processed at $7.7 \mathrm{Gpa}$, the major component of the binding energy for the Si $2 p$ environment remained practically unchanged compared to the pristine sample but new components, with smaller intensities, appeared in the spectra, indicating the existence of distinct Q-species induced by high pressure. This behavior may be related to changes in the number of bridged and non-bridged oxygen atoms in the glass structure. The results for the second group of samples, crystallized under high pressure, showed evidences of three binding energies for the $\mathrm{O}$ atoms, one of them related to non-bridged and two of them to bridged $\mathrm{O}$ atoms.
\end{abstract}

Keywords: XPS; Glass Ceramic; Lithium Disilicate; High Pressure; Binding Energy

\section{Introduction}

Structural analysis of glasses under high pressure is important to understand the effect of densification mechanisms on the glass properties [1]. Bridgman et al. [2] pointed out that the permanent densification after applying high pressure and high temperature (HPHT) is a phenomenon observed only for glassy materials due to their structural freedom.

Kitamura et al. [1] investigated the densification of lithium disilicate $\mathrm{Li}_{2} \mathrm{O} \cdot 2 \mathrm{SiO}_{2}\left(\mathrm{LS}_{2}\right)$ glasses at $6 \mathrm{GPa}$ and $400^{\circ} \mathrm{C}$. Based on Raman spectroscopy and radial distribution function, they attributed the densification to an increase of the packing density of $\mathrm{SiO}_{4}$ tetrahedra due to a decrease of the Si-O-Si bond angle between the tetrahedra. They showed the Si-O-Si bond angle decreased from $109.8^{\circ}$ to $108.8^{\circ}$ and the Si-O length increased by $0.001 \mathrm{~nm}$.

Schmelzer et al. [3] discussed the pressure dependence of viscosity and free volume of liquids in frozen systems in non-equilibrium states. According to them, the viscosity of simple liquids typically increased with pressure.

The crystallization of $\mathrm{LS}_{2}$ under HPHT has been stud- ied in the past few years [1,4-11]. In previous works, the effect of densification on the crystallization process and thermal properties of $\mathrm{LS}_{2}$ glass was investigated [4], as well as the effect of pressure and temperature on the mechanical [5] and optical [6] properties. It was observed that the hardness and elastic modulus of the sample processed at HPHT increased noticeably compared to the samples crystallized at atmospheric pressure. The refractive index of $\mathrm{LS}_{2}$ was also significantly affected by HPHT.

Nuclear Magnetic Resonance (NMR) results obtained by Fuss et al. [9] indicated the formation of lithium metasilicate solid solution (LS-ss) for samples submitted to $6 \mathrm{GPa}$ and thermal treatment below $750^{\circ} \mathrm{C}$. According to the authors, the difference between lithium metasilicate (MS) and LS-ss was not detectable by X-ray diffraction since there were no changes in the crystal symmetry of both structures. The difference would be related to the number of bridged (BO) and non-bridged (NBO) oxygen atoms. Buchner et al. [6], on the other hand, showed the formation of crystalline MS after processing $\mathrm{LS}_{2}$ at 7.7 $\mathrm{GPa}$ and $455 / 500^{\circ} \mathrm{C}$ for nucleation followed by $610^{\circ} \mathrm{C}$ for crystal growing. 
Adams \& De Jong [12] investigated the early stages of crystallization of a slightly hyper stoichimetric $\mathrm{LS}_{2}$ sample $\left(34.5 \mathrm{~mol} \% \mathrm{Li}_{2} \mathrm{O}\right)$ at $450^{\circ} \mathrm{C}$ using $\mathrm{X}$-ray photoelectron spectroscopy (XPS) and they ascribed the presence of an extra Li 1s peak in the XPS spectrum $(\sim 51.7 \mathrm{eV})$ to the formation of a MS phase. Soares et al. [13], however, repeated the XPS analysis at the same conditions and concluded that this extra Li 1s peak was related to contamination. Moreover, they concluded that XPS was not a suitable technique to detect structural changes in $\mathrm{LS}_{2}$ when the volume fraction of the crystals was very low. On the other hand, the formation of the MS phase in the early stages of nucleation was confirmed by them using TEM analysis [14].

Nesbitt et al. [15] investigated the chemical environment around $\mathrm{Na} 1 \mathrm{~s}, \mathrm{O}$ 1s and $\mathrm{Si} 2 \mathrm{p}$ atoms in $\mathrm{Na}_{2} \mathrm{O}-\mathrm{SiO}_{2}$ glass as a function of the glass composition. Six compositions of $\mathrm{Na}_{2} \mathrm{O}-\mathrm{SiO}_{2}$ glass ranging from 100 to $45 \mathrm{~mol} \%$ $\mathrm{SiO}_{2}$ were investigated by XPS and NMR. The Si $2 \mathrm{p}_{3 / 2}$ peak maximum shifted to lower binding energy (BE) with increasing $\mathrm{Na}_{2} \mathrm{O}$ content. According to the authors, the $\mathrm{BE}$ shift indicated increased valence electron density on the Si nuclei with increased $\mathrm{Na}_{2} \mathrm{O}$ concentration. Each Q-species should yield a peak at slightly different BE since the electron density over each $\mathrm{Si}$ atom should be different, depending on the number of $\mathrm{BO}$ and NBO bonded to it.

According to Sawyer et al. [16], the BE of the Q-species are strongly affected by the number of NBO bonded to the $\mathrm{Si}$ atom, with $\mathrm{BE}$ decreasing systematically from $\mathrm{Q}^{4}$ to $\mathrm{Q}^{0}$ species. They observed the shift of the peak toward lower $\mathrm{BE}$ with increasing $\mathrm{K}_{2} \mathrm{O}$ content in $\mathrm{K}_{2} \mathrm{O}-\mathrm{SiO}_{2}$ glass. Two doublets in the $\mathrm{Si} 2 \mathrm{p}$ spectra of different glass compositions were identified. According to the authors, the strongly asymmetric nature of the $\mathrm{Si}$ $2 p$ spectra of the potasic glasses may result from two or more Q-species contributions to the Si $2 \mathrm{p}$ spectra and the intensity of the doublet would depend on the amount of the particular Q-specie.

In this context, the aim of this work was to investigate the effect of high pressure on the chemical environment of $\mathrm{Si} 2 \mathrm{p}, \mathrm{O} 1 \mathrm{~s}$ and $\mathrm{Li} 1 \mathrm{~s}$ atoms of the $\mathrm{LS}_{2}$ glass structure using XPS to help elucidate the mechanisms responsible for the early stages of the formation of the metasilicate structure induced by densification. For comparison, the chemical environment of these atoms was also investigated after complete crystallization of the glass structure under high pressure and high temperature.

\section{Experimental Procedure}

\subsection{Sample Preparation}

Lithium disilicate glass of stoichiometric composition $\mathrm{Li}_{2} \mathrm{O} \cdot 2 \mathrm{SiO}_{2}\left(\mathrm{LS}_{2}\right)$ was prepared using standard reagent grade $\mathrm{Li}_{2} \mathrm{CO}_{3}$ (Aldrich Chem. Co., 99+\%) and ground quartz $\left(<99.9 \% \mathrm{SiO}_{2}\right)$. The $200 \mathrm{~g}$ batch was melted in a Pt crucible at $1450^{\circ} \mathrm{C}$ during 2 hours in an electric furnace. The melt was poured on a steel plate, annealed below the glass transition temperature, at $430^{\circ} \mathrm{C}$, during $1 \mathrm{~h}$ and cooled down slowly to room temperature.

\subsection{High Pressure Experiments}

The HP experiments were performed in a toroidal high pressure apparatus. The specific configuration and type of high-pressure chamber used in the experiments were optimized for providing quasi-hydrostatic pressure [17]. The pressure calibration was carried out by the "fixedpoints" technique using $\mathrm{Bi}$ and $\mathrm{Yb}$, which permitted the calibration of the pressure at the following points: $\mathrm{Bi}$ with phase transitions at $2.5 \mathrm{GPa}$ and $7.7 \mathrm{GPa}$, and $\mathrm{Yb}$ with a phase transition at $4.0 \mathrm{GPa}$. A detailed description of the high-pressure calibration method has been provided elsewhere [17].

During the HPHT experiments, a monolithic $\mathrm{LS}_{2}$ sample was placed inside a hexagonal boron nitride (hBN) capsule which acted as a soft pressure transmitting medium. The hBN capsule was placed inside a graphite cylinder which acted as a heater element. For experiments performed at HP and room temperature (HPRT), the capsule of hBN was replaced by a lead capsule, which is a softer pressure transmitting compared to $\mathrm{hBN}$.

In the first group, the samples were submitted to 2.5 $\mathrm{GPa}, 4 \mathrm{GPa}$ and $7.7 \mathrm{GPa}$ at room temperature during 5 min inside the lead capsule. In the second group, the samples were submitted to $\mathrm{HP}(2.5,4.0$ and $7.7 \mathrm{GPa})$ inside the hBN capsule and, simultaneously, to the following thermal treatment: $500^{\circ} \mathrm{C}$ during $2 \mathrm{~h}$ for nucleation followed by $610^{\circ} \mathrm{C}$ during $0.5 \mathrm{~h}$ for crystal growing. For comparison, a pristine glass sample and a sample submitted to the same heat treatment at $1 \mathrm{~atm}$ were also investigated.

According to a previous work [6], the processing at 2.5 $\mathrm{GPa}$ and high temperature induced the crystallization of the monoclinic phase of lithium disilicate $\left(\mathrm{Li}_{2} \mathrm{Si}_{2} \mathrm{O}_{5}\right)$. At 4.4 GPa it was observed the formation of the orthorhombic phase with the same stoichiometry and, at $7.7 \mathrm{GPa}$ the glass structure crystallized as $\mathrm{MS}\left(\mathrm{Li}_{2} \mathrm{SiO}_{3}\right)$.

After HPRT and HPHT processing, the surface of the samples was grounded on $\mathrm{SiC}$ abrasive paper up to $\# 1200$ and polished with $\mathrm{CeO}_{2}$ slurry for XPS analyses.

\subsection{Analytical Techniques-XPS}

XPS analyses were performed in an Omicron-SPHERA station using $\mathrm{Al} \mathrm{K} \alpha$ radiation $(1486.6 \mathrm{eV})$. The anode was operated at $225 \mathrm{~W}(15 \mathrm{kV}, 15 \mathrm{~mA})$. Survey spectra were recorded with a $50 \mathrm{eV}$ pass energy. Si $2 \mathrm{p}, \mathrm{O} 1 \mathrm{~s}$, and $\mathrm{Li} 1 \mathrm{~s}$ regions were recorded with high resolution (pass 
energy of $20 \mathrm{eV}$ ). The detection angle of the photoelectrons $(\Theta)$ with respect to the sample surface (take-off angle) was fixed at $53^{\circ}$ for all measurements. The $\mathrm{C} 1 \mathrm{~s}$ signal from adventitious carbon at $284.6 \mathrm{eV}$ was used as an internal energy reference. All spectra were fitted assuming a Shirley background. Lines were fitted by $70 \%$ Gaussian $+30 \%$ Lorentzian functions with set values of full width at half maximum for each line.

\section{Results and Discussion}

\subsection{Densification at Room Temperature (HPRT)}

Figures 1-3 show high resolution XPS spectra for Si 2p, $\mathrm{O} 1 \mathrm{~s}$ and $\mathrm{Li} 1 \mathrm{~s}$, respectively, after processing at high pressure compared to the pristine sample. It is clearly seen that the BE of the three elements changed irreversible after densification, revealing the strong influence of high pressure in the chemical environment due to the structural freedom of the glassy $\mathrm{LS}_{2}$.

According to Figure 1, Si $2 \mathrm{p}$ presents two doublets from 2.5 to $7.7 \mathrm{GPa}$, corresponding to $\mathrm{Si} 2 \mathrm{p}_{3 / 2}$ and $\mathrm{Si}$ $2 \mathrm{p}_{1 / 2}$. However, the intensity and $\mathrm{BE}$ of each doublet changed with pressure. Figure 2 shows that there is practically only one $\mathrm{BE}$ component for $\mathrm{O} 1 \mathrm{~s}$ up to $2.5 \mathrm{GPa}$,

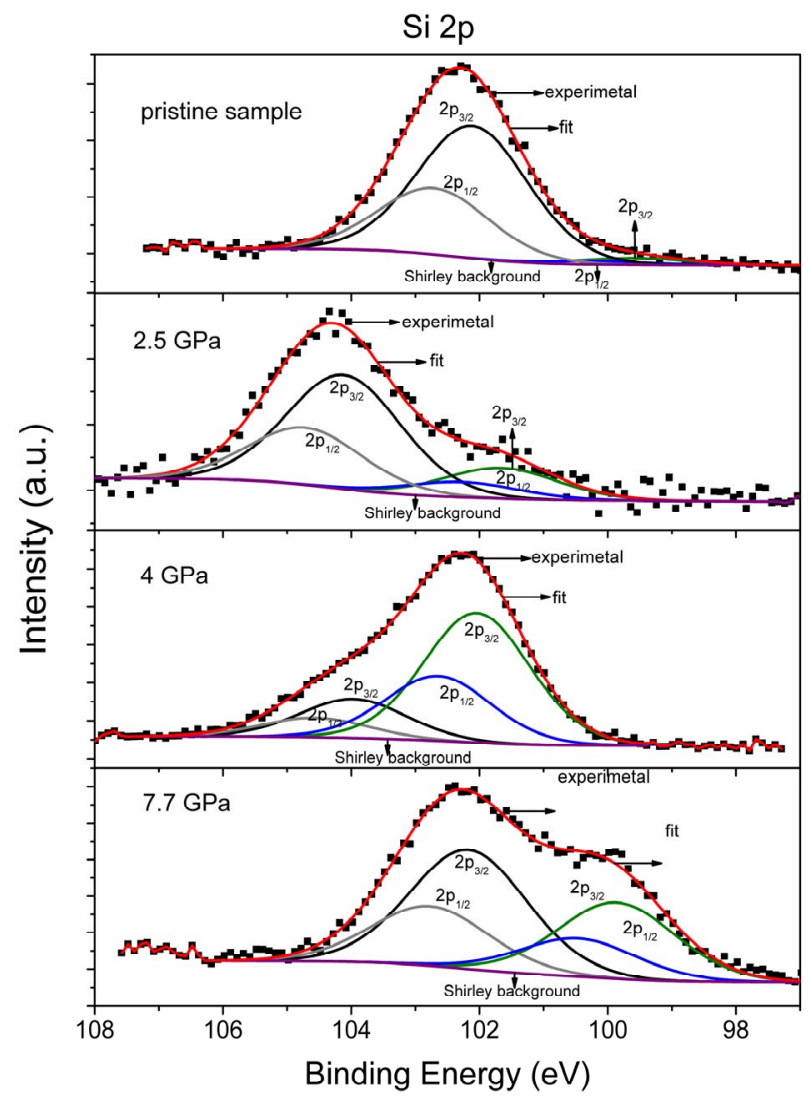

Figure 1. Si 2p region of XPS spectrum of the $L S_{2}$ pristine sample and after processing at $2.5 \mathrm{GPa}, 4 \mathrm{GPa}$, and $7.7 \mathrm{GPa}$ at room temperature.

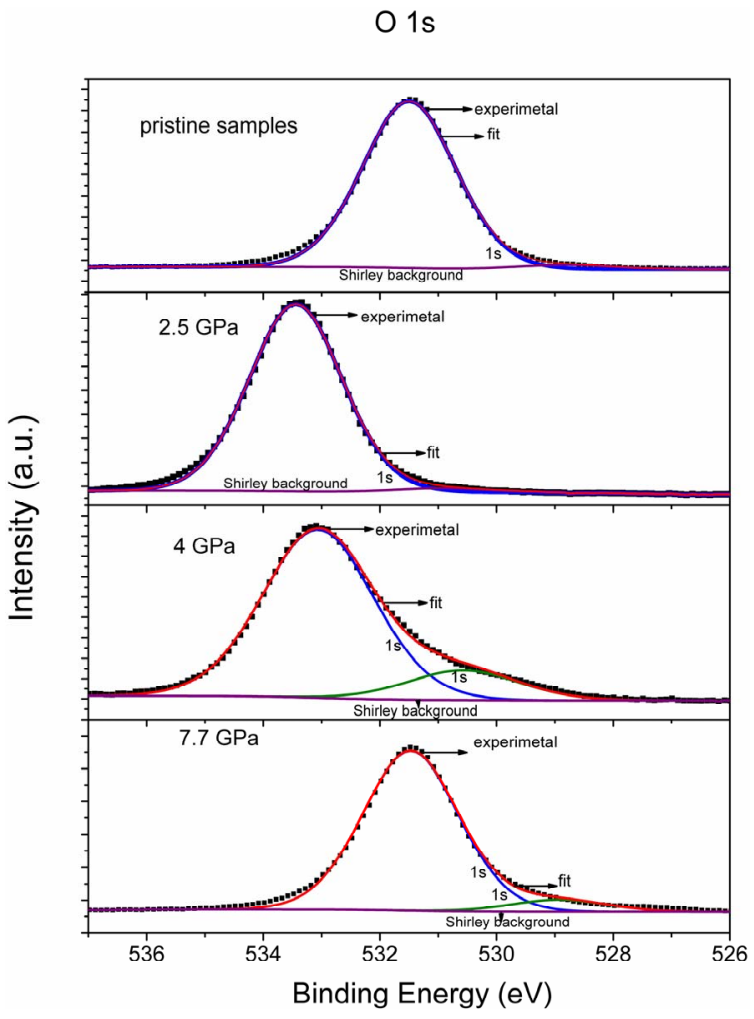

Figure 2. $O$ 1s region of XPS spectrum of the $L_{2}$ pristine sample and after processing at $2.5 \mathrm{GPa}, 4 \mathrm{GPa}$, and $7.7 \mathrm{GPa}$ at room temperature.

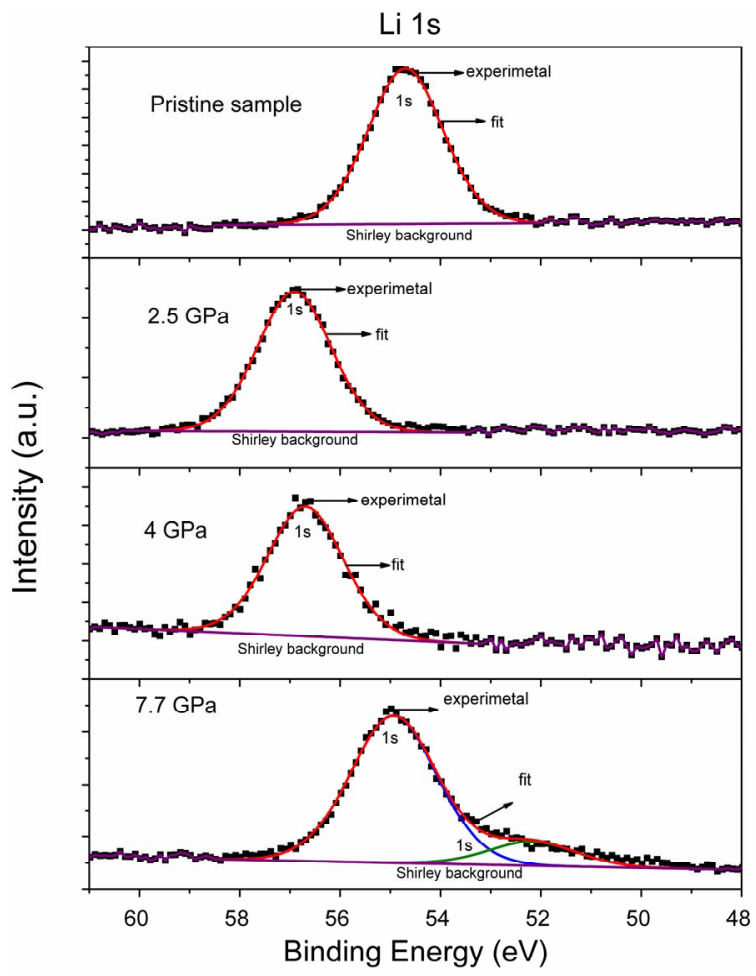

Figure 3. $\mathrm{Li}$ 1s region of XPS spectrum of the $\mathrm{LS}_{2}$ pristine sample and after processing at $2.5 \mathrm{GPa}, 4 \mathrm{GPa}$, and $7.7 \mathrm{GPa}$ at room temperature. 
while after processing at 4 and $7.7 \mathrm{GPa}$ there are two components. In these cases, the component with higher intensity corresponds to $\mathrm{BO}$ while the lower intensity component corresponds to NBO. For Li atoms (Figure 3), only at $7.7 \mathrm{GPa}$ it is possible to identify a second component of BE.

Table 1 shows the values of the BE obtained in this work by fitting the experimental data compared to the results found in the literature for $\mathrm{LS}_{2}$.

\subsection{Crystallization under High Pressure (HPHT)}

Figures 4-6 show the XPS results for the samples crystallized under high pressure. In this case there was practically no shift in the BE as a function of pressure.

Figure 4 shows that the formation of doublets for $\mathrm{Si}$ $2 p_{3 / 2}$ and $S i 2 p_{1 / 2}$ now happens only after processing at 7.7 GPa. Figure 5 shows that there were three components of $\mathrm{BE}$ for $\mathrm{O} 1 \mathrm{~s}$ up to $7.7 \mathrm{GPa}$, one associated to $\mathrm{NBO}$ and two associated to BO. The intensity of the component with higher $\mathrm{BE}$ decreases with increasing pressure. For Li atoms (Figure 6), only at 7.7 GPa it was possible to identify a component of the BE. Soares et al.
[18] already reported that the detection of the Li 1s XPS signal from crystalline samples of $\mathrm{LS}_{2}$ was difficult.

The BE measured for the pristine glass sample and for the crystalline sample obtained at atmospheric pressure are similar to the results found in the literature $[12,13,18]$, as shown in Table 1. The permanent shift of the BE toward higher energy and the change in the intensity of the peaks for Li 1s, O 1s and Si 2p observed in Figures 1-3 indicated that the densification affects irreversibly the glass structure, even without crystallization.

The large shift of the BE toward higher energies observed for Si $2 p$ after processing at 2.5 and $4 \mathrm{GPa}$ (Figure 1) suggests a stronger interaction with the surrounding oxygen atoms compared to the pristine glass. According to Sawyer et al. [16], the BE decreases systematically from $\mathrm{Q}^{4}$ to $\mathrm{Q}^{0}$ species for $\mathrm{Si} 2 \mathrm{p}$. According to Figure 1, two Q-species were observed in all samples for Si $2 p$, but for pristine samples the intensity of the Q-species of lower energy was very small. Probably in pristine glass samples the $\mathrm{Q}^{3}$ specie was dominant and the small peak of lower energy corresponded to residual $\mathrm{Q}^{2}$ species.

Table 1. Binding energy values obtained from the fitting of the XPS experimental data for the samples processed under high pressure at room temperature (glass) and processed under high pressure and high temperature (glass ceramic) compared to the results found in the literature at $1 \mathrm{~atm}$.

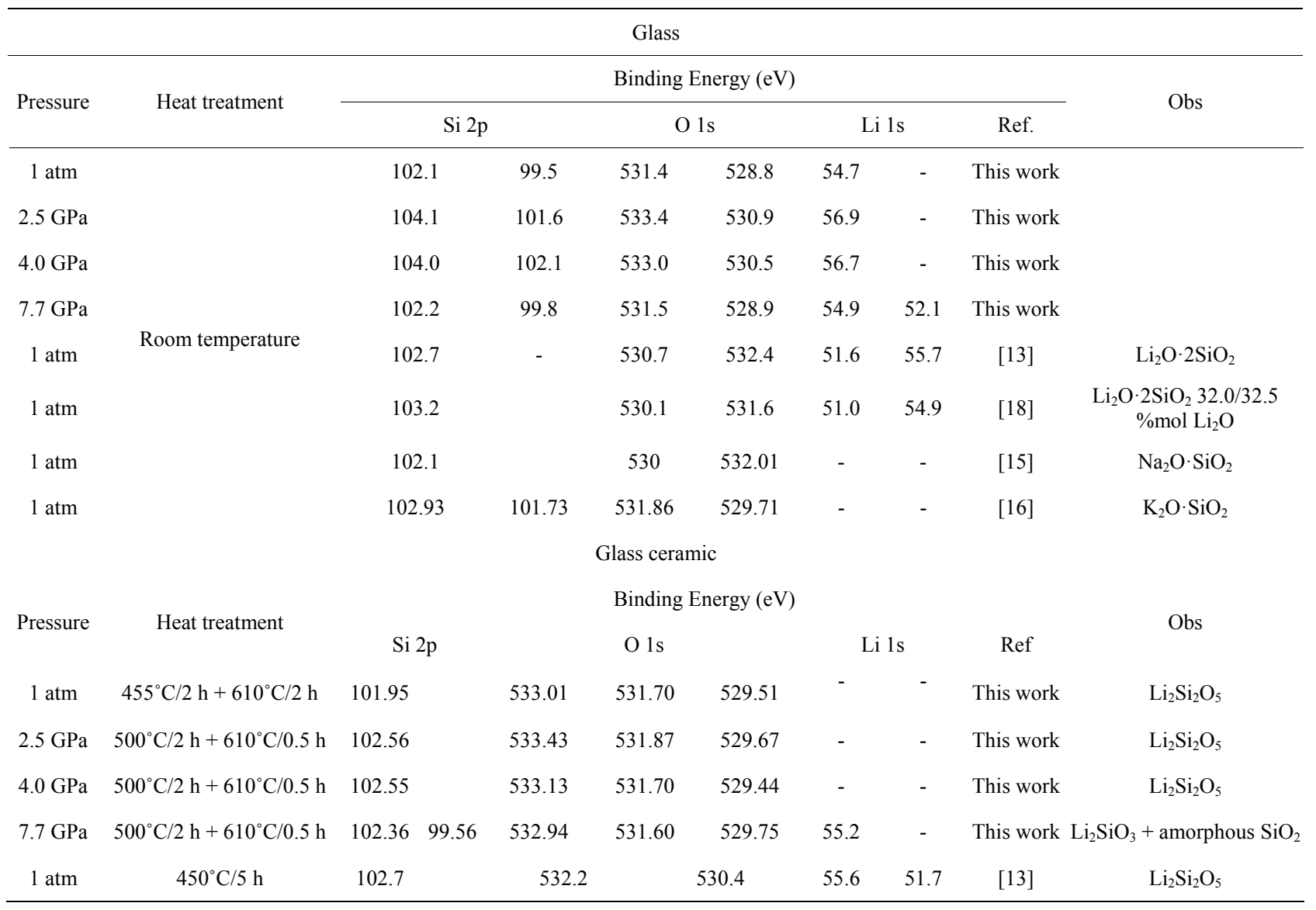




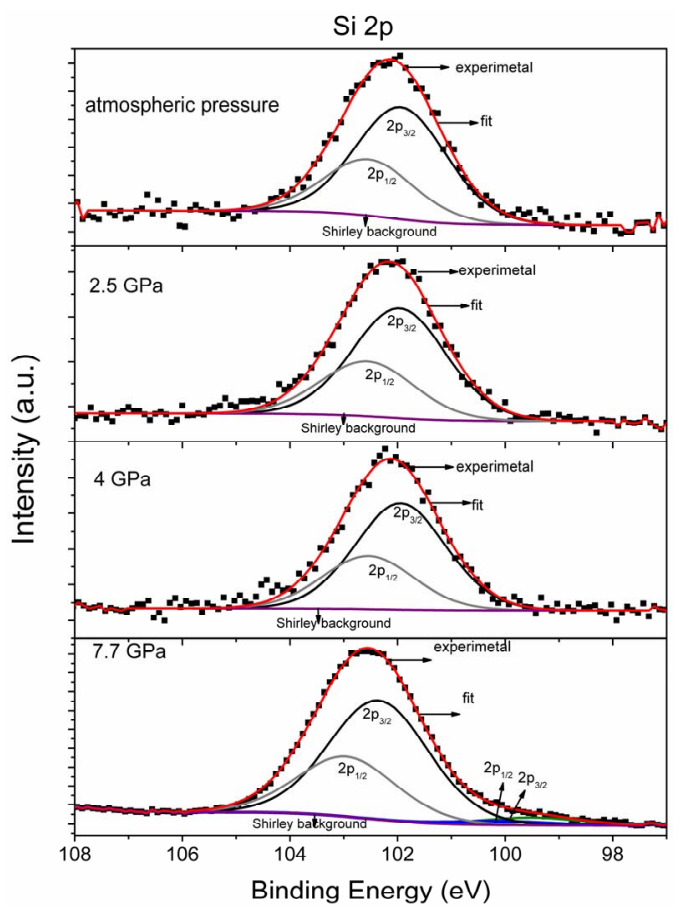

Figure 4. Si 2p XPS spectra obtained from crystalline samples produced at atmospheric pressure, $2.5 \mathrm{GPa}, 4 \mathrm{GPa}$, and $7.7 \mathrm{GPa}$. The thermal treatment was: $500^{\circ} \mathrm{C}$ during $2 \mathrm{~h}$ for nucleation followed by $610^{\circ} \mathrm{C}$ during $0.5 \mathrm{~h}$ for crystal growing.

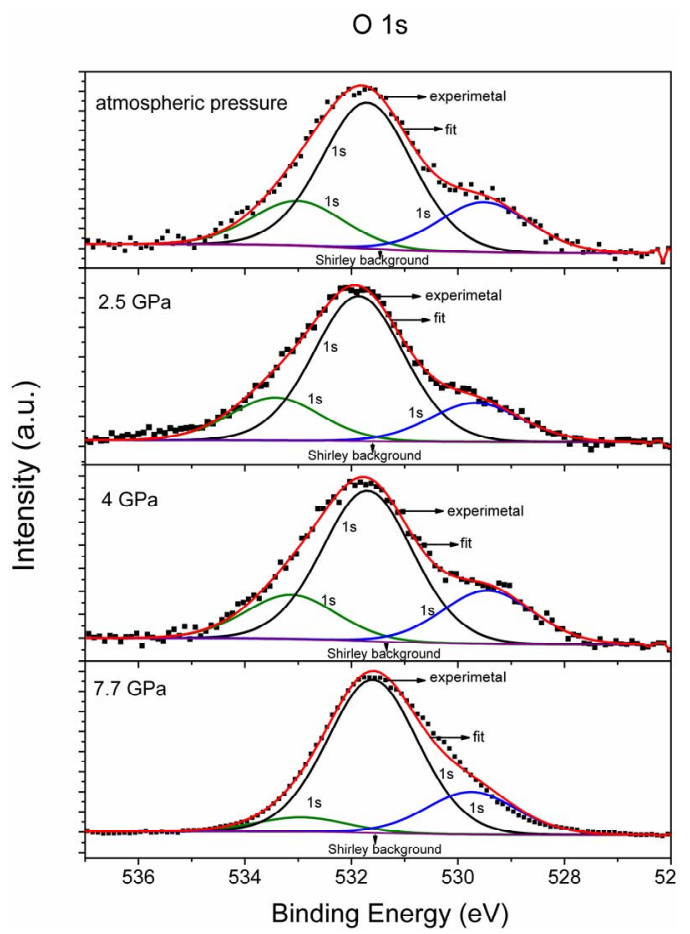

Figure 5. O 1s XPS spectra obtained from crystalline samples produced at atmospheric pressure, $2.5 \mathrm{GPa}, 4 \mathrm{GPa}$, and 7.7 GPa. The thermal treatment was: $500^{\circ} \mathrm{C}$ during $2 \mathrm{~h}$ for nucleation followed by $610^{\circ} \mathrm{C}$ during $0.5 \mathrm{~h}$ for crystal growing.

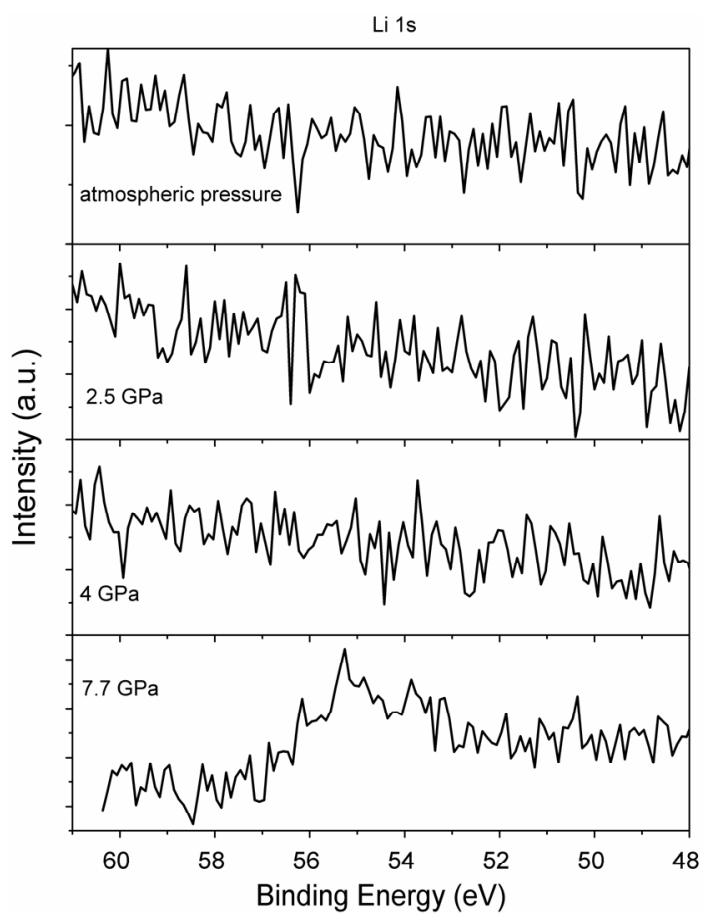

Figure 6. Li 1s XPS spectra obtained from crystalline samples produced at atmospheric pressure, $2.5 \mathrm{GPa}, 4 \mathrm{GPa}$, and $7.7 \mathrm{GPa}$. The thermal treatment was: $500^{\circ} \mathrm{C}$ during $2 \mathrm{~h}$ for nucleation followed by $610^{\circ} \mathrm{C}$ during $0.5 \mathrm{~h}$ for crystal growing.

In the case of $\mathrm{O} 1 \mathrm{~s}$ atoms (Figure 2), the peak at higher energy $(\sim 531 \mathrm{eV})$ for the pristine sample corresponds to $\mathrm{BO}$ atoms ( $\mathrm{Si}-\mathrm{O}-\mathrm{Si}$ ) while the other component $(\sim 528.8 \mathrm{eV})$ corresponds to the NBO atoms (Si-O-Li) $[13,19]$. After processing at 2.5 and $4 \mathrm{GPa}$ the BE of the BO atoms shifted irreversibly to higher energies, indicating a larger interaction with the $\mathrm{Si}$ atoms, in agreement with the behavior of the Si $2 p$ XPS spectrum. The intensity of the peak related to the NBO atoms was very low for the pristine sample and after processing at 2.5 $\mathrm{GPa}$ the intensity of this peak slightly increased after processing at 4 and $7.7 \mathrm{GPa}$, probably indicating a decomposition of the $\mathrm{Q}^{3}$ into the $\mathrm{Q}^{2}$ species at higher pressure.

Figure 3 shows that the BE for Li 1 s also shifted after processing at $2.5 \mathrm{GPa}$ and $4 \mathrm{GPa}$, and a second component at $52.1 \mathrm{eV}$ was detected after processing at $7.7 \mathrm{GPa}$. According to Adams \& De Jong [12,20], this component may be related to a local arrangement that would be favorable to the formation of the metastable phase during heat treatment.

Considering the XPS spectra for crystalline samples produced under high pressure, Figure 4 shows that the $\mathrm{Si}$ $2 p$ presents only one chemical environment related to $Q^{3}$ species formed during crystallization of lithium disilicate $\left(\mathrm{Li}_{2} \cdot \mathrm{Si}_{2} \mathrm{O}_{5}\right)$. The $\mathrm{Si} 2 \mathrm{p}_{3 / 2}$ spectrum for the sample crystallized at $7.7 \mathrm{GPa}$, however, presents a doublet indicating 
the formation of two structures, one of them related to lithium metasilicate $\mathrm{Li}_{2} \cdot \mathrm{SiO}_{3}$ and the other, to residual $\mathrm{SiO}_{2}$ to satisfy stoichiometric restrictions [6].

For O 1s (Figure 5), the smaller BE corresponds to the NBO atoms (Si-O-Li) $[13,19]$ and it was observed for all pressure range investigated. For pressures up to $4 \mathrm{GPa}$, the intensity and energy of this peak remained practically unchanged, compatible with the formation of crystalline lithium disilicate. At $7.7 \mathrm{GPa}$, it was observed a small shift of this component toward higher energy and a slight decrease of its intensity. This result is in agreement with the changes observed in the spectrum for $\mathrm{Si} 2 \mathrm{p}$ at the same pressure, indicating a distinct configuration of Q-species at higher pressures.

Two peaks related to $\mathrm{BO}$ atoms, of higher $\mathrm{BE}$, were observed for all pressure range in the crystalline samples. The most intense component was probably related to $\mathrm{Si}-\mathrm{O}-\mathrm{Si}$ and the other one may be related to BO-Li. Ching et al. [21] also observed two types of BO atoms in crystalline $\mathrm{Na}$ disilicate. According to them, one type was assigned to $\mathrm{Si}-\mathrm{O}-\mathrm{Si}$ as in vitreous silica whereas the other type of $\mathrm{BO}$ atom was also bonded to a $\mathrm{Na}$ atom with the BO-Na bond length being similar to the NBO$\mathrm{Na}$ bond length [22]. Du and Cormack [23] and Mountjoy [24] investigated by molecular dynamics simulations the formation of two BO in sodic glasses. The experimental results obtained by Nesbitt et al. [15] for sodic glass also provided evidences for two types of $\mathrm{BO}$, one bonded to two $\mathrm{Si}$ atoms and one bonded to a $\mathrm{Na}$ atom as well as to two Si atoms. Sawyer et al. [16] reported that the width of the O 1s XPS peak was highly variable and wider than that of the NBO peak for potasic glass. The variable width would be a consequence of the presence of two types of $\mathrm{BO}$ atoms with somewhat different BE; one type bridged to two $\mathrm{Si}$ atoms while the other type bridged to three atoms, two Si and one $\mathrm{K}$ atom. According to the authors, the abundance of the two types of BO atoms was similar to the abundance of $\mathrm{Q}^{4}$ and $\mathrm{Q}^{3}$ species of previous NMR studies.

Fuss et al. [9] observed that at $4.5 \mathrm{GPa}$ and high temperature, $\mathrm{LS}_{2}$ crystallized as the lithium disilicate phase, consisting only of $\mathrm{Q}^{3}$ tetrahedra, but the NMR results indicated the presence of a small amount of $\mathrm{Q}^{2} \mathrm{SiO}_{4}$ tetrahedra, which could be a glassy or crystalline phase acting as imperfections. In the present work, the crystallization at $4 \mathrm{GPa}$ induced the formation of only the $\mathrm{Q}^{3}$ species in the Si $2 p$ spectrum, without any evidence of residual $\mathrm{Q}^{2}$. At $6 \mathrm{GPa}$, the results obtained by Fuss et al. suggested that the $\mathrm{LS}_{2}$ glass densified under pressure and crystallized as a single new phase with a higher density, resembling a slightly deformed MS phase. For this sample, they observed one sharp $\mathrm{Q}^{2}$ peak in the NMR spectrum associated with crystalline $\mathrm{MS}$, a broad $\mathrm{Q}^{4}$ band related to glassy $\mathrm{SiO}_{2}$ and a broad $\mathrm{Q}^{3}$ band associated with the residual glass. Additionally, they found four more peaks related to $\mathrm{Q}^{3}$ and $\mathrm{Q}^{4}$ tetrahedra that could not be related to residual glass. Based on the NMR, Raman and IR results, they suggested the formation of a crystalline lithium metasilicate solid-solution having the same symmetry of MS but formed out of three different tetrahedral species. In this solid solution, four Li ions from the metasilicate structure would be statistically replaced by one $\mathrm{Si}$ ion and three vacancies, without changing the crystal symmetry. This replacement would be detected by a shift of the peaks in the XRD pattern related to the change in lattice parameters that was, in fact, observed by the authors and corroborated by the NMR results about the amount of BO and NBO atoms. The XPS results found in the present work for the sample crystallized at $7.7 \mathrm{GPa}$ indicated two chemical environments around $\mathrm{Si}$ atoms, associated with $\mathrm{Q}^{3}$ species of lithium metasilicate $\left(\mathrm{Li}_{2} \mathrm{SiO}_{3}\right)$ and $\mathrm{Q}^{2}$ associated to residual $\mathrm{SiO}_{2}$. No evidences of other $\mathrm{Q}$ species were observed. Maybe the reason for the differences between the consistent results found by Fuss et al. [9] and the results found in this work is related to the thermal treatment: they investigated temperatures from $608^{\circ} \mathrm{C}$ during $20 \mathrm{~min}$ up to $753^{\circ} \mathrm{C}$ during $60 \mathrm{~min}$ at $6 \mathrm{GPa}$. In this work we considered $500^{\circ} \mathrm{C}$ during $2 \mathrm{~h}$ for nucleation followed by $0.5 \mathrm{~h}$ at $610^{\circ} \mathrm{C}$ for crystal growing, both under high pressure. Probably the higher temperatures used by Fuss et al. [9] were not suitable for nucleation of the crystalline phases, resulting in a solid solution favored at higher temperatures where the average Si-O-Si bonding angle would decrease and there would be at least four different $\mathrm{Si}$ sites, according to the NMR results.

\section{Conclusion}

Densification of lithium disilicate at room temperature under high pressure induced large and irreversible modifications in the chemical environment of Si 2p, O 1s and Li 1s. These modifications would be related to the rearrangement of the atoms induced by high pressure due to the structural freedom of the glass structure, even at room temperature. XPS showed to be a suitable technique to detect the structural changes induced by densification at room temperature. For samples crystallized under high pressure, it was observed that a similar behavior for pressures up to $4 \mathrm{GPa}$, related to the formation of monoclinic and orthorhombic lithium disilicate. The in- terpretation of the XPS results for $\mathrm{Si} 2 \mathrm{p}$ and $\mathrm{O} 1 \mathrm{~s}$ for the sample crystallized at $7.7 \mathrm{GPa}$ was consistent with the formation of lithium metasilicate and $\mathrm{SiO}_{2}$.

\section{Acknowledgements}

The authors would like to thank CNPq, CAPES and 
FAPERGS for the financial support and to LaMaV for the fusion of the samples.

\section{REFERENCES}

[1] N. Kitamura, K. Fukumi, H. Mizoguchi, M. Makihara, A. Higuchi, N. Ohno and T. Fukunaga, "High Pressure Densification of Lithium Silicate Glasses," Journal of NonCrystalline Solids, Vol. 274, No. 3, 2000, pp. 244-248. doi:10.1016/S0022-3093(00)00190-3

[2] P. W. Bridgmann and I. Simon, "Effects of Very High Pressures on Glass," Journal of Applied Physics, Vol. 24, No. 4, 1953, pp. 405-413. doi:10.1063/1.1721294

[3] J. W. P. Schmelzer, E. D. Zanotto and V. M. Fokin, "Pressure Dependence of Viscosity," The Journal of Chemical Physics, Vol. 122, No. 7, 2005, Article ID: 074511. doi:10.1063/1.1851510

[4] S. Buchner, P. Soares, A. S. Pereira, E. B. Ferreira and N. M. Balzaretti, "Effect of High Pressure in the $\mathrm{Li}_{2} \mathrm{O}-2 \mathrm{SiO}_{2}$ Crystallization," Journal of Non-Crystalline Solids, Vol. 356, No. 52-54, 2010, pp. 3004-3308. doi:10.1016/j.jnoncrysol.2010.02.027

[5] S. Buchner, C. M. Lepienski, P. C. Soares Jr. and N. M. Balzaretti, "Effect of High Pressure on the Mechanical Properties of Lithium Disilicate Glass Ceramic," Materials Science and Engineering: A, Vol. 528, No. 10-11, 2011, pp. 3921-3924. doi:10.1016/j.msea.2011.01.095

[6] S. Buchner, M. B. Pereira and N. M. Balzaretti, "Behavior of the Refractive Index of Lithium Disilicate Glass Ceramic Processed at High Pressure and High Temperature," Optical Materials, Vol. 34, No. 5, 2012, pp. 826831. doi:10.1016/j.optmat.2011.11.018

[7] S. Buchner, "Efeito de Altas Pressões na Astrutura e nas Aropriedades da Vitrocerâmica Dissilicato de Lítio," Ph.D. Thesis, Federal University of Rio Grande do Sul, São José, 2011. http://hdl.handle.net/10183/35171

[8] T. Fuss, C. S. Ray, N. Kitamura, M. Makihara and D. E. Day, "Pressure Induced Nucleation in $\mathrm{Li}_{2} \mathrm{O} \cdot 2 \mathrm{SiO}_{2}$ Glass," Journal of Non-Crystalline Solids, Vol. 318, No. 1-2, 2003, pp. 157-167. doi:10.1016/S0022-3093(02)01878-1

[9] T. Fuss, A. Mogus-Milanković, C. S. Ray, C. E. Lesher, R. Youngman and D. E. Day, "Ex Situ XRD, TEM, IR, Raman and NMR Spectroscopy of Crystallization of Lithium Disilicate Glass at High Pressure," Journal of NonCrystalline Solids, Vol. 352, No. 38, 2006, pp. 41014111. doi:10.1016/j.jnoncrysol.2006.06.038

[10] T. Fuss, C. S. Ray, C. E. Lesher and D. E. Day, "In Situ Crystallization of Lithium Disilicate Glass: Effect of Pressure on Crystal Growth Rate," Journal of Non-Crystalline Solids, Vol. 352, No. 21-22, 2006, pp. 2073-2081. doi:10.1016/j.jnoncrysol.2006.03.005

[11] I. Gutzow, B. Durschang and C. Russel, “ Crystallization of Glass Forming Melts under Hydrostatic Pressure and Shear Stress Part I. Crystallization Catalysis under Hydrostatic Pressure: Possibilities and Limitations" Journal of Materials Science, Vol. 32, No. 20, 1997, pp. 53895403. doi:10.1023/A:1018683331603
[12] J. W. Adams and B. H. W. S. De Jong, Materials Research Society 1993 Fall Meeting Symposium Proceedings, Vol. 321, 1994, p. 339.

[13] P. C. Soares, P. A. P. Nascente and E. D. Zanotto, "XPS Study of Lithium Disilicate Glass Crystallisation," Physics and Chemistry of Glasses, Vol. 43, No. 3, 2002, pp. 143-146.

[14] P. C. Soares, E. D. Zanotto, V. M. Fokin and H. Jain, "TEM and XRD Study of Early Crystallization of Lithium Disilicate Glasses," Journal of Non-Crystalline Solids, Vol. 331, No. 1-3, 2003, pp. 217-227. doi:10.1016/j.jnoncrysol.2003.08.075

[15] H. W. Nesbitt, G. M. Bancroft, G. S. Henderson, R. Ho, K. N. Dalby, Y. Huang and Z. Yan, "Bridging, NonBridging and Free $\left(\mathrm{O}^{2-}\right)$ Oxygen in $\mathrm{Na}_{2} \mathrm{O}-\mathrm{SiO}_{2}$ Glasses: An X-Ray Photoelectron Spectroscopic (XPS) and Nuclear Magnetic Resonance (NMR) Study," Journal of Non-Crystalline Solids, Vol. 357, No. 1, 2011, pp. 170180. doi:10.1016/j.jnoncrysol.2010.09.031

[16] R. Sawyer, H. W. Nesbitt and R. A. Secco, "High Resolution X-Ray Photoelectron Spectroscopy (XPS) Study of $\mathrm{K}_{2} \mathrm{O}-\mathrm{SiO}_{2}$ Glasses: Evidence for Three Types of $\mathrm{O}$ and at Least Two Types of Si," Journal of Non-Crystalline Solids, Vol. 358, No. 2, 2012, pp. 290-302. doi:10.1016/j.jnoncrysol.2011.09.027

[17] M. I. Eremets, "High Pressure Experimental Methods," Oxford University Press, New York, 1996.

[18] P. C. Soares, "Mecanismos de Cristalização em Vidros Disilicato de Lítio," Ph.D. Thesis, Universidade Federal de São Carlos, Brazil, 2002.

[19] R. Brückner, H. U. Chun, H. Goretzki and M. Sammet, "XPS Measurements and Structural Aspects of Silicate and Phosphate Glasses," Journal of Non-Crystalline Solids, Vol. 42, No. 1-3, 1980, pp. 49-60. doi:10.1016/0022-3093(80)90007-1

[20] J. W. Adams, "Morphogenesis in Lithium Disilicate Glass: Internal Nucleation in Amorphous Structure," Ph.D. Thesis, University of Cambridge, Cambridge, 1993.

[21] W. Y. Ching, R. A. Murray, D. J. Lam and B. W. Veal, "Comparative Studies of Electronic Structures of Sodium Metasilicate and $\alpha$ and $\beta$ Phases of Sodium Disilicate," Physics Review B, Vol. 28, No. 8, 1983, pp. 4724-4735. doi:10.1103/PhysRevB.28.4724

[22] A. K. Pant and D. W. J. Cruickshank, "The Crystal Structure of $\alpha-\mathrm{Na}_{2} \mathrm{Si}_{2} \mathrm{O}_{5}$," Acta Crystallographica Section B, Vol. 24, No. 13-19, 1968, pp. 13-19. doi: $10.1107 / \mathrm{S} 0567740868001640$

[23] J. Du and A. N. Cormack, "The Medium Range Structure of Sodium Silicate Glasses: A Molecular Dynamics Simulation," Journal of Non-Crystalline Solids, Vol. 349, 2004, pp. 66-79. doi:10.1016/j.jnoncrysol.2004.08.264

[24] G. Mountjoy, "The Local Atomic Environment of Oxygen in Silicate Glasses from Molecular Dynamics," Journal of Non-Crystalline Solids, Vol. 353, No. 18-21, 2007, pp. 1849-1853. doi:10.1016/j.jnoncrysol.2007.01.051 